\title{
H. Glenn Penny, Im Schatten Humboldts. Eine tragische Geschichte der deutschen Ethnologie
}

Hélène Ivanoff

\section{OpenEdition}

Journals

Édition électronique

URL : http://journals.openedition.org/ifha/10478

DOI : $10.4000 /$ ifha. 10478

ISSN : 2198-8943

Éditeur

IFRA - Institut franco-allemand (sciences historiques et sociales)

Référence électronique

Hélène Ivanoff, « H. Glenn Penny, Im Schatten Humboldts. Eine tragische Geschichte der deutschen Ethnologie », Revue de l'IFHA [En ligne], Date de recension, mis en ligne le 21 novembre 2019, consulté le 24 septembre 2020. URL : http://journals.openedition.org/ifha/10478 ; DOI : https://doi.org/ 10.4000/ifha. 10478

Ce document a été généré automatiquement le 24 septembre 2020.

(C)IFHA 


\section{H. Glenn Penny, Im Schatten} Humboldts. Eine tragische Geschichte der deutschen Ethnologie

Hélène Ivanoff

\section{RÉFÉRENCE}

H. Glenn Penny, Im Schatten Humboldts. Eine tragische Geschichte der deutschen Ethnologie, München : C. H. Beck, 2019, 288 p., 27,80€ 
Dans l'ombre de Humboldt, l'histoire tragique de l'ethnologie allemande est le dernier livre de l'historien américain, H. Glenn Penny, spécialiste de l'histoire de cette discipline et de ses musées. Il est entre autres l'auteur de Objects of culture: Ethnology and Ethnographic Museums in Imperial Germany (2002) et de Worldly Provincialism: German Anthropology in the Age of Empire (2003). Invité au Wissenschaftkolleg de Berlin en 2017-2018, le chercheur a été le témoin de la virulence des débats concernant la création du Humboldt Forum, nouveau musée dédié aux cultures extraeuropéennes au cœur de la capitale allemande, dont l'ouverture a été repoussée à septembre 2020.

Avec la nuance et l'érudition propre à l'historien des sciences, il revient sur la fondation du Museum für Völkerkunde de

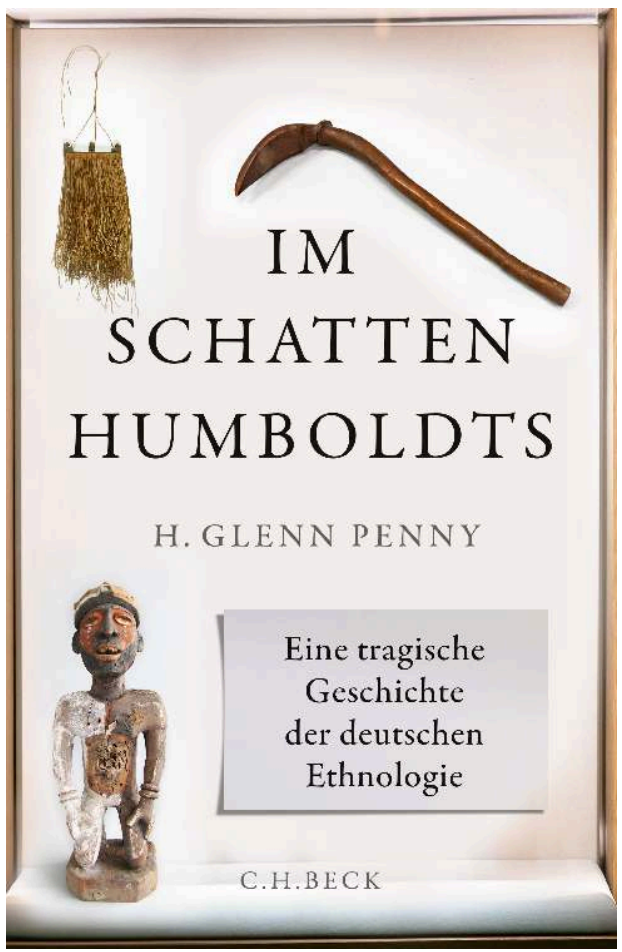
Berlin et la constitution de ses collections, aujourd'hui encore parmi les plus importantes au monde, avec ses quelques 500000 objets, dont une très faible partie sera exposée dans les salles du Humboldt Forum. Dans ce contexte, les collections ethnographiques contemporaines ont été discréditées et stigmatisées, en raison de la compromission décrétée et supposée de l'ethnologie allemande avec le colonialisme, et donc avec les massacres et les pillages qui lui sont associés.

H. G. Penny retrace la tragédie de cette science qui s'est affirmée comme la protectrice de la diversité et de la richesse culturelle au XIX ${ }^{\mathrm{e}}$ siècle, et ceci bien avant que l'Allemagne ne devienne une puissance coloniale en 1884, pour voir actuellement les musées ethnographiques allemands être accusés d'être, même indirectement, partie prenante dans le pillage des colonies et d'avoir participé à la spoliation du patrimoine culturel des États du Sud. Des idéaux humanistes des frères Humboldt du début du XIX ${ }^{\mathrm{e}}$ siècle aux suspicions entourant la mise en place du Humboldt Forum au début du XXI ${ }^{\mathrm{e}}$, l'ethnologie allemande est sommée de justifier de ses actes pendant la période coloniale.

C'est pourquoi l'historien américain évoque dans ce livre les parcours, qualifiés de "destins tragiques", d'ethnologues allemands de la fin du XIX et du début du XX siècles, avides de sauvegarder la culture matérielle des sociétés traditionnelles sous emprise coloniale, et dont les collections rassemblées au Museum für Völkerkunde de Berlin suscitent, encore de nos jours, des contestations et des demandes de restitution. Il se penche en effet sur les cas de différents explorateurs et scientifiques ayant contribué à la mise en place et à l'enrichissement des collections ethnographiques, à savoir Adolf Bastian (1826-1905), Adrian Jacobsen (1853-1947), Franz Boas (1858-1942), Felix von Luschan (1854-1924) et Franz Termer (1894-1968).

Le choix s'est donc porté sur les pionniers de la discipline, premiers ethnographes confrontés au terrain et pères fondateurs de l'ethnologie en tant que science 
académique en Allemagne, offrant aux lecteurs un panorama de la constitution des collections en Amérique du Nord, centrale et du Sud, en Océanie et en Afrique. H. G. Penny décrit avec une grande précision les collectes réalisées par ces ethnologues, amateurs puis scientifiques confirmés, sans rien cacher des recherches en anthropologie physique menées au XIX ${ }^{\mathrm{e}}$ siècle sur la notion de race, ni des acquisitions faites par le musée ethnographique de Berlin à la suite des pillages coloniaux.

Bien au contraire, il montre comment la constitution des collections de crânes et d'os ont servi à contester les paradigmes de l'époque, en particulier le racisme et l'évolutionnisme. Pour paraître scandaleuses aujourd'hui, ces collections anthropologiques n'en ont pas moins été, à la transition du XIX et du XXe siècles, une ressource essentielle pour contester l'idée qu'il pouvait exister des races inférieures et supérieures. C'est bien grâce aux recherches menées par les pionniers de l'ethnologie à partir de ces collections que l'idée d'une "unité psychique de l'humanité » s'est imposée - notamment sous la houlette d'A. Bastian et de F. von Luschan - ou que le principe de l'égalité des cultures et le relativisme culturel sont devenus des fondements de l'anthropologie sociale et culturelle américaine, par l'intermédiaire de l'ethnologue allemand émigré aux États-Unis, Franz Boas.

De même, l'auteur ne nie nullement les liens ambivalents des ethnologues allemands avec les soldats et les administrateurs coloniaux, maillons indispensables et essentiels dans la chaîne des transferts matériels et intellectuels entre les scientifiques et les populations locales. Il qualifie même les accords passés entre le Museum für Völkerkunde de Berlin et ces derniers de "pacte avec le diable». En effet, le musée bénéficia d'un monopole et d'une priorité d'achats sur les objets venant des colonies allemandes, encourageant les dons et les ventes des agents coloniaux. Les ethnologues allemands prétendaient parallèlement pratiquer une " ethnologie de sauvetage » sur le terrain et tentaient de "sauver » des pillages coloniaux tout ce qui pouvait l'être encore, persuadés que la colonisation mènerait à l'extinction des sociétés traditionnelles et à la disparition de leurs cultures matérielles et spirituelles.

Enfin, l'auteur prend position dans le débat concernant le projet contesté du Humboldt Forum, rappelant combien il est éloigné de la vision de Humboldt et des pionniers de l'ethnologie. Il critique la méconnaissance régnant autour de l'histoire des collections ethnographiques et leur instrumentalisation politique, tant du côté des partisans que des détracteurs du nouveau musée. Il met aussi en exergue la récurrence des thèmes et des arguments, pratiquement inchangés par rapport au début du $\mathrm{XX}^{\mathrm{e}}$ siècle, quand Wilhelm von Bode (1845-1929) vint contrecarrer les ambitions de A. Bastian pour le Museum für Völkerkunde de Berlin, en prônant par exemple d'exposer des pièces "chefs-d'œuvre ", la séparation des collections exposées et étudiées, ou encore l'exclusion des collections asiatiques des collections ethnographiques qui, elles, devaient avoir leur propre musée.

Il déplore que le projet coûteux du Humboldt Forum n'ait pas consacré une partie de ses financements à la recherche de provenance, notamment à l'histoire des collections pendant la période coloniale. Pour conclure, il salue les initiatives de conservateurs de musées ethnographiques ayant établi, en dépit d'un maigre budget, des coopérations avec les communautés d'origine. Leur but était de retracer l'histoire et d'éclairer la signification de collections qui, après avoir été convoitées et assemblées massivement dans l'Europe coloniale, sont demeurées, parfois pendant des décennies, dans les caisses des entrepôts de Dahlem, avant d'être redécouvertes et étudiées. 
Au-delà des polémiques contemporaines et des jugements impartiaux concernant la constitution des collections extra-européennes et leur patrimonialisation en Europe, la réalité historique s'avère, comme bien souvent, plus riche et complexe. Il revient à H. Glenn Penny le mérite d'apporter un peu de lumière sur ce passé enfoui dans l'ombre de Humboldt.

\section{INDEX}

Index chronologique : Époque contemporaine

Thèmes : Histoire de l'art, Histoire de la culture, Histoire des mentalités 